\title{
Perception of quantity and quality of sleep and their association with health related quality of life and life satisfaction during adolescence
}

\author{
Margarida Gaspar de Matos ${ }^{1,2,3 *}$, Adilson Marques ${ }^{1,2,4}$, Tania Gaspar ${ }^{1,2,5,6}$ and Teresa Paiva ${ }^{2,6}$ \\ ${ }^{1}$ Faculdade de Motricidade Humana, Universidade de Lisboa, Lisboa, Portugal \\ ${ }^{2}$ Instituto de Saúde Ambiental, Faculdade de Medicina, Universidade de Lisboa, Lisboa, Portugal \\ ${ }^{3}$ WJCR/Istituto Superior de Psicologia Aplicada, Lisboa, Portugal \\ ${ }^{4}$ Centro de Investigação em Saúde Pública, Escola Nacional de Saúde Pública, Universidade Nova de Lisboa, Lisboa, Portugal \\ ${ }^{5}$ Escola de Psicologia, Universidade Lusíada, Lisboa, Portugal \\ ${ }^{6}$ Centro de Eletroencefalografia e Neurofisiologia Clínica - Centro do Sono, Lisboa, Portugal
}

\begin{abstract}
Objectives: This study aims to analyse differences between sleep duration and sleep quality and their association with health related quality of life and life satisfaction during adolescence.

Methods: The Health Behaviour in School-Aged Children (HBSC) survey is based on a self-completed questionnaire. The participants in the present study were 3631 students (53.1\% were girls) in the 8 th and 10 th grades at school; the mean age was 14.8 years (range 13-18).

Results: The present results add to previous ones that both the duration and the perceived quality of sleep have impact upon the perception of quality of life and the perception of life satisfaction.

Conclusions: These results are substantially important for sleep hygiene and for recommendations for adolescents, parents, health and education professionals and public policies. It is now widely recommended that adolescents must sleep at least 8 hours per night, what this study allow to recommend is that the perception of quality of that sleep is equally important, and this leads to another set of recommendations to increase sleep quality, that include not exercising or practising sports in the evenings, avoiding conflicts at home in the evenings, no going to bed worried, no having caffeine and other energetic drinks in the evening, not abusing screen time after dinner or in bed. These recommendations are important to assure sleep duration and perceived quality and therefore the perception of wellness and life satisfaction, having an additional impact on health and on school achievement.
\end{abstract}

\section{Introduction}

This study aims to analyse the differences between sleep duration and sleep quality and their association with health related quality of life and life satisfaction during adolescence. A brief revision of the concerned sleep parameters (duration, quality) that may impact upon health and health related quality of life and life satisfaction of adolescents is made.

Several studies of children and adolescents have pointed out the relations of sleep duration with: daytime sleepiness [1-3], body mass index (BMI) [2,4-7], type II diabetes and insulin resistance [8], sleep disorders [1], health characteristics [2], high blood pressure [9], pain [10-12], cognitive tests and academic success [3,13-16], subjective psychological wellbeing $[17,18]$, socioeconomic status $[2,5]$, habits such as high screen or TV viewing time $[5,16,19,20]$, low or moderate physical activity $[5,21]$, poor dietary intake and quality $[20,22]$, and risk-taking behaviours [19,23-28]. Some studies considered not only the parameter sleep duration, but also sleep deprivation, considering sleep deprivation the difference between week-days sleep duration and week-ends sleep duration $[16,18,19]$.

In a recent meta-analysis of children and adolescents aged from 9 to 18 years, including 23 countries, sleep duration varied with gender, age, and geographical region [29]. School-day sleep differed slightly between boys and girls - girls slept for $11 \mathrm{~min} /$ night more than boys, and $29 \mathrm{~min}$ more on non-school days. Sleep time declined with age - minus $14 \mathrm{~min} /$ day per year of age on school days, and $7 \mathrm{~min}$ on nonschool days.

In Finland, using a very large sample of adolescents $(\mathrm{n}=384,076)$ aged 14 to 20 years, it was found that late bedtimes, especially after 11:30 $\mathrm{pm}$, increase the prevalence of depression, accidents, neck or shoulder pain, low back pain, stomach-ache, anxiety or nervousness, irritability or tantrums, headaches, tiredness or dizziness [30].Insomnia is also a risk for pain chronicity, while pain, poor sleep hygiene, and higher depressive symptoms are the main risks for insomnia persistence [31]. Fatigue is another important associated symptom, often associated

Correspondence to: Michael Malone, Penn State Hershey Department of Family and Community Medicine, USA; Penn State College of Medicine, USA, Tel: 717531-8181; E-mail: mmalone@hmc.psu.edu

Key words: sleep duration, sleep quality, health

Received: February 14, 2017; Accepted: March 10, 2017; Published: March 13, 2017 
with depression and insomnia or sleep problems [32-34]. Fatigue is significantly associated with feeling depressed, with poor breakfast habits, with not being well in school, with low physical activity and with no adult to talk to, interpersonal violence and delinquent actions $[16,33]$ and a mutual interaction between depression and sleep also exists $[18,19]$.

Well-being and health-related quality of life (HRQoL) in children and adolescents are quite recent concepts [18]. It is important to consider these concepts within an ecological perspective throughout multiple levels of analysis, namely self-perceptions and family perceptions [35]. Children's perceptions of their HRQoL are influenced by several factors, such as gender, age, personal and family characteristics and resilience, as well as their socio-economic status (SES) [35-39].

Healthy sleep is fundamental to human health and quality of life $[39,40]$, and sleep deprivation increases the risk for mood and behavioural problems, such as drug and alcohol use and vulnerability to accidents [16-20,23-26, 41].

Links between eveningness and poor physical, social/ interpersonal relationships and mental health have also been found [42]. Adolescents with poor sleeping patterns present lower scores on emotional, social, school, psychosocial functioning and poor global perception of quality of life, when compared with same age adolescents without poor sleeping patterns [16-20,43-45]. Those with delayed sleep phase disorders have higher trends for alcohol and caffeine consumption, and lower sports participation [46]. Sleeping for 6 hours or less per night is linked to symptoms of depression and lower self-esteem [47]. Sleep deprivation is associated with deficits in child and adolescent functioning, and global health $[48,49]$. Children and adolescents who sleep for less than 5 hours per night present with more feelings of stress, depression, and suicidal ideation [50,51].

Thus this study focus both on sleep duration and sleep quality analysing their impact on health related quality of life and life satisfaction during adolescence.

\section{Methods}

\section{Study design, participants and procedures}

This is a cross-sectional study based on data from the Health Behaviour in School-Aged Children (HBSC) Portuguese survey conducted in 2014 [52]. HBSC is a World Health Organization study conducted every 4 years in nationally representative school-based samples [53]. HBSC examines a number of health behaviours and lifestyles and their context in young people. The Portuguese HBSC in 2014 survey included a representative sample of 6026 adolescents. For the current study only students from grades 8 and 10 where included because grade 6 did not answer the sleep group of questions. The final sample size included thus 3631 adolescents (46.9\% boys), aged 13-18 years (mean age $=14.8 \pm 1.2$ ).

The survey consisted of a self-administered questionnaire that was completed in public schools. The schools were randomly selected from a national list, which had been geographically stratified by administrative and educational regional divisions. The administration of the surveys was conducted according to standard guidelines from the HBSC survey protocol $[53,54]$, and was carried out by trained teachers during class time. School administrators, legal guardians, and adolescents gave a written consent. Adolescents' participation was voluntary, anonymous, and there were no incentives for participation. Research was conducted in accordance with both the Ethical Committee of Oporto Medical
School and the National Data Protection System.

\section{Measures}

Adolescents' socio-demographic characteristics included gender, school grade, and age. Adolescents were asked how many hours, in average, they sleep, per night during a weekday. Based on responses, a new variable was computed according sleep time duration recommendations [55], and sleep duration was dichotomised into $<8$ hours/night and $\geq 8$ hours/night. Adolescents were also asked how often their sleep was "good". Response options were never/almost never, sometimes, and almost always/always.

HRQL was assessed by KIDscreen-10 [56-58]. It contains 10 items regarding family life, peers, and school life and results from a longer version developed in the context of an international project, and it is currently used in the context of the HBSC survey [56-58]. The 10 items result in one global score, after having reverted two single items (feeling sad and feeling alone), that were formulated in the direction opposite to wellbeing. This one-dimensional measure represents a global score adequate for use in large (epidemiological) surveys, such as HBSC. To identify the opinions about Life Satisfaction, the Cantril SelfAnchoring Striving Scale [59] was used. Adolescents indicated where they stood on a 10-point ladder, with zero being the worst possible life and ten being the best possible life. Based on HRQL/Kidscreen 10 and life satisfaction responses, adolescents were classified as having low or high HRQL and life satisfaction according to the median value. The perception of adolescents about their health was collected through the question, "You would say your health is...?" Answers were given, through selection, on a 4-point scale (poor, fair, good, and excellent) [60].

\section{Data analysis}

Descriptive statistics (means, standard deviation and percentages) were calculated for the entire sample, and according to gender. Ordinal variables were treated as continuous variables, thus, they were tested for normality. Student t-test and Chi square were used to assess the differences between gender, sleep duration, sleep quality, HRQL, as per KIDscreen-10 score and life satisfaction. The comparison between sleeping duration ( $<8$ hours/night vs. $\geq 8$ hours/night), and perceived sleep quality, according HRQL/KIDSreen-10 (for each item and for total score) and life satisfaction, ANCOVA was performed; age and gender were used as covariates, and school classes as random effect. The relationship of HRQL/KIDScreen-10 and life satisfaction with sleep duration time in its continuous form, sleep 8 or more hours per night and having good night of sleep were analysed using binary logistic regression. The regression analyses were adjusted for age, gender and health perception. Statistical analyses were performed using IBM SPSS Statistics 22.0. The level of significance was set at 0.05 .

\section{Results}

Table 1 shows the sample characteristics, sleep duration, quality of sleep, HRQL/KIDScreen-10 and life satisfaction results for the general sample and stratified by gender. The sleep duration was in average $7.8 \pm$ 1.1 hours/night ( $7.9 \pm 1.1$ for boys vs. $7.7 \pm 1.1$ for girls, $p<0.001)$. Most of adolescents reported to have always a good night of sleep (63.8\%), and the difference between boys and girls was significant (69.7\% for boys vs. $58.5 \%$ for girls, $p<0.001)$. Gender differences were also observed in HRQL and life satisfaction: the total score of HRQL was $37.6 \pm 6.5$ (39.0 \pm 6.4 for boys vs. $36.3 \pm 6.4$ for girls, $p<0.001)$ and life satisfaction was $7.2 \pm 1.9(7.4 \pm 1.8$ for boys vs. $7.0 \pm 1.9$ for girls, $p<0.001$ ) (Table 1 ). 
Table 1. Characteristics for total sample and stratified by gender.

\begin{tabular}{|c|c|c|c|c|}
\hline & $\begin{array}{c}\text { Total }(n=3631) \\
M \pm \text { SD or } n(\%)\end{array}$ & $\begin{array}{c}\text { Boys }(n=1704) \\
M \pm \text { SD or n }(\%)\end{array}$ & $\begin{array}{c}\text { Girls (n=1927) } \\
M \pm \text { SD or n (\%) }\end{array}$ & $p$ \\
\hline Age & $14.8 \pm 1.2$ & $14.8 \pm 1.2$ & $14.8 \pm 1.2$ & 0.705 \\
\hline $\begin{array}{l}\text { School year } \\
8^{\text {th }} \text { grade } \\
10^{\text {th }} \text { grade } \\
\end{array}$ & $\begin{array}{l}2187(60.2) \\
1444(39.8)\end{array}$ & $\begin{array}{l}1072(62.9) \\
632(37.1)\end{array}$ & $\begin{array}{l}1115(57.9) \\
812(42.1)\end{array}$ & 0.002 \\
\hline Sleep duration (hr/night) & $7.8 \pm 1.1$ & $7.9 \pm 1.1$ & $7.7 \pm 1.1$ & $<0.001$ \\
\hline $\begin{array}{l}\text { Good night of sleep } \\
\text { Never } \\
\text { Sometimes } \\
\text { Always }\end{array}$ & $\begin{array}{c}146(4.0) \\
11169(32.2) \\
2316(63.8)\end{array}$ & $\begin{array}{c}66(3.9) \\
450(26.4) \\
1188(69.7)\end{array}$ & $\begin{array}{c}80(4.2) \\
719(719) \\
1128(58.5)\end{array}$ & $<0.001$ \\
\hline $\begin{array}{l}\text { HRLQ } \\
\text { Felt fit and well } \\
\text { Felt full of energy } \\
\text { Felt sad } \\
\text { Felt lonely } \\
\text { Had enough time for yourself } \\
\text { Being able to do things in free time } \\
\text { Parent(s) treated you fairly } \\
\text { Have fun with your friends } \\
\text { Get on well at school } \\
\text { Been able to pay attention }\end{array}$ & $\begin{array}{l}3.8 \pm 1.1 \\
3.7 \pm 1.1 \\
2.5 \pm 1.1 \\
2.0 \pm 1.1 \\
3.6 \pm 1.1 \\
3.6 \pm 1.2 \\
4.1 \pm 1.1 \\
4.2 \pm 0.9 \\
3.6 \pm 0.9 \\
3.5 \pm 1.0\end{array}$ & $\begin{array}{l}4.1 \pm 1.0 \\
3.9 \pm 1.0 \\
2.2 \pm 1.0 \\
1.9 \pm 1.0 \\
3.8 \pm 1.1 \\
3.9 \pm 1.2 \\
4.1 \pm 1.1 \\
4.2 \pm 0.9 \\
3.6 \pm 1.0 \\
3.6 \pm 1.0\end{array}$ & $\begin{array}{l}3.6 \pm 1.1 \\
3.4 \pm 1.0 \\
2.8 \pm 1.0 \\
2.2 \pm 1.1 \\
3.5 \pm 1.1 \\
3.4 \pm 1.2 \\
4.0 \pm 1.1 \\
4.2 \pm 0.9 \\
3.6 \pm 0.9 \\
3.5 \pm 0.9\end{array}$ & $\begin{array}{l}<0.001 \\
<0.001 \\
<0.001 \\
<0.001 \\
<0.001 \\
<0.001 \\
0.024 \\
0.585 \\
0.993 \\
0.001\end{array}$ \\
\hline HRLQ/KIDScrren-10 score & $37.6 \pm 6.5$ & $39.0 \pm 6.4$ & $36.3 \pm 6.4$ & $<0.001$ \\
\hline Life satisfaction & $7.2 \pm 1.9$ & $7.4 \pm 1.8$ & $7.0 \pm 1.9$ & $<0.001$ \\
\hline
\end{tabular}

Abbreviation: M, mean; SD, standard deviation; hr, hours; HRQL, health-related quality of life.

Differences between gender were tested by Chi-square and Independent Sample T Test.

Table 2. Relationship between HRQL and life satisfaction with sleep duration and sleep quality.

\begin{tabular}{|c|c|c|c|c|c|c|c|}
\hline & \multicolumn{3}{|c|}{ Sleep duration } & \multicolumn{4}{|c|}{ Perception of Sleep quality (good night of sleep) } \\
\hline & $<8$ hours/night & $\geq 8$ hours/night & $p$ & Never & Sometimes & Always & $p$ \\
\hline $\begin{array}{l}\text { HRLQ } \\
\text { Felt fit and well } \\
\text { Felt full of energy } \\
\text { Felt sad } \\
\text { Felt lonely } \\
\text { Had enough time for yourself } \\
\text { Being able to do things in free time } \\
\text { Parent(s) treated you fairly } \\
\text { Had fun with your friends } \\
\text { Got on well at school } \\
\text { Been able to pay attention }\end{array}$ & $\begin{array}{l}3.6 \pm 1.2 \\
3.4 \pm 1.1 \\
2.7 \pm 1.1 \\
2.2 \pm 1.1 \\
3.4 \pm 1.2 \\
3.4 \pm 1.3 \\
3.9 \pm 1.1 \\
4.1 \pm 1.0 \\
3.4 \pm 1.0 \\
3.3 \pm 1.0\end{array}$ & $\begin{array}{l}4.0 \pm 1.0 \\
3.8 \pm 1.0 \\
2.4 \pm 1.0 \\
1.9 \pm 1.0 \\
3.8 \pm 1.1 \\
3.8 \pm 1.2 \\
4.2 \pm 1.1 \\
4.3 \pm 0.9 \\
3.7 \pm 0.9 \\
3.7 \pm 0.9\end{array}$ & $\begin{array}{c}<0.001 \\
<0.001 \\
<0.001 \\
<0.001 \\
<0.001 \\
<0.001 \\
0.014 \\
<0.001 \\
<0.001 \\
<0.001\end{array}$ & $\begin{array}{l}2.9 \pm 1.4 \\
2.7 \pm 1.3 \\
3.1 \pm 1.3 \\
2.6 \pm 1.3 \\
2.8 \pm 1.2 \\
2.8 \pm 1.3 \\
3.5 \pm 1.3 \\
3.6 \pm 1.3 \\
3.0 \pm 1.1 \\
2.8 \pm 1.1\end{array}$ & $\begin{array}{l}3.5 \pm 1.1 \\
3.3 \pm 1.0 \\
2.9 \pm 1.0 \\
2.3 \pm 1.1 \\
3.3 \pm 1.1 \\
3.3 \pm 1.2 \\
3.8 \pm 1.1 \\
4.0 \pm 1.0 \\
3.4 \pm 0.9 \\
3.3 \pm 0.9\end{array}$ & $\begin{array}{l}4.1 \pm 1.0 \\
3.9 \pm 1.0 \\
2.3 \pm 1.0 \\
1.8 \pm 1.0 \\
3.9 \pm 1.1 \\
3.8 \pm 1.2 \\
4.3 \pm 1.1 \\
4.4 \pm 0.9 \\
3.7 \pm 0.9 \\
3.7 \pm 0.9\end{array}$ & $\begin{array}{l}<0.001 \\
<0.001 \\
<0.001 \\
<0.001 \\
<0.001 \\
<0.001 \\
<0.001 \\
<0.001 \\
<0.001 \\
<0.001\end{array}$ \\
\hline HRLQ score & $35.3 \pm 6.7$ & $38.9 \pm 6.1$ & $<0.001$ & $30.3 \pm 7.4$ & $34.7 \pm 6.1$ & $39.5 \pm 5.8$ & $<0.001$ \\
\hline Life satisfaction & $6.7 \pm 2.0$ & $7.4 \pm 1.8$ & $<0.001$ & $5.9 \pm 2.5$ & $6.6 \pm 2.0$ & $7.5 \pm 1.7$ & $<0.001$ \\
\hline
\end{tabular}

\section{Tested by ANCOVA.}

Analysis were adjusted for age, gender and health perception.

The relationship of sleep duration and perceived sleep quality with HRQL/KIDScreen-10 and life satisfaction are presented in table 2. Adolescents who spent $\geq 8$ hours of nigh sleep had significantly better HRQL/KIDScreen-10 score $(\mathrm{F}(3,3624)=220.120, p<0.001)$ and life satisfaction $(\mathrm{F}(3,3624)=100.066, p<0.001)$. Both for the total and for all the single items of HRQL/ KIDScreen-10, adolescents who spend more time sleeping per night had higher values, and those who reported to have the perception of having always good night of sleep had better scores, except for feeling sad and lonely, whose score was reverted before summing: HRQL score $(\mathrm{F}(4,3623)=322.723, p<0.001)$ and life satisfaction $(\mathrm{F}(4,3623)=122.177, p<0.001)($ Table 2$)$.

Table 3 shows the results of the logistic regression models that analysed the relationship of sleep duration and perceived sleep quality with HRQL/KIDScreen-10 and life satisfaction. Sleep duration was positively related with having high HRQL/KIDScreen-10 ( $\mathrm{OR}=1.35$, 95\% CI: $1.26-1.45, \mathrm{p}<0.001)$ and high life satisfaction $(\mathrm{OR}=1.27,95 \%$ CI: $1.19-1.35, \mathrm{p}<0.001)$. Similarly, sleeping $\geq 8$ hours per night increase the likelihood of having high HRQL/KIDScreen-10 (OR=1.97, 95\% CI: $1.69-2.30, \mathrm{p}<0.001)$ and high life satisfaction $(\mathrm{OR}=1.71,95 \% \mathrm{CI}: 1.47-$
$1.89, \mathrm{p}<0.001)$. As for the perception of sleep quality, to have always a good night of sleep was also associated with higher odds for high HRQL/KIDScreen-10 (OR=3.07, 95\% CI: 2.63-3.59, $\mathrm{p}<0.001)$ and high life satisfaction $(\mathrm{OR}=1.91,95 \% \mathrm{CI}: 1.65-2.21, \mathrm{p}<0.001)$. Similarly, when analysing the HRQL/KIDScreen-10 single items, eight out of then of them were positive and significantly related to adequate sleep duration and perceived quality; as expected only the negative oriented items (reporting feeling sad or lonely) were negative and significantly related with sleep time duration (sleeping $\geq 8$ hours per night), and having the perception of always having a good night sleep (Table 3 ).

\section{Discussion}

Although most of adolescents reported to have always the perception of having had a good night of sleep, girls report poor perception of sleep quality and according to this study and also less quantity sleep, result not confirming previous studies that state that girls tend to sleep more [29], this fact must be due to participant age differences and because of a different estimation of sleep duration. As stated in several previous studies girls' perception of HRQOL/KIDScreen-10 is 
Table 3. Logistic regression model of HRQL/KIDScreen-10, life satisfaction with sleep duration and perception of good sleep quality.

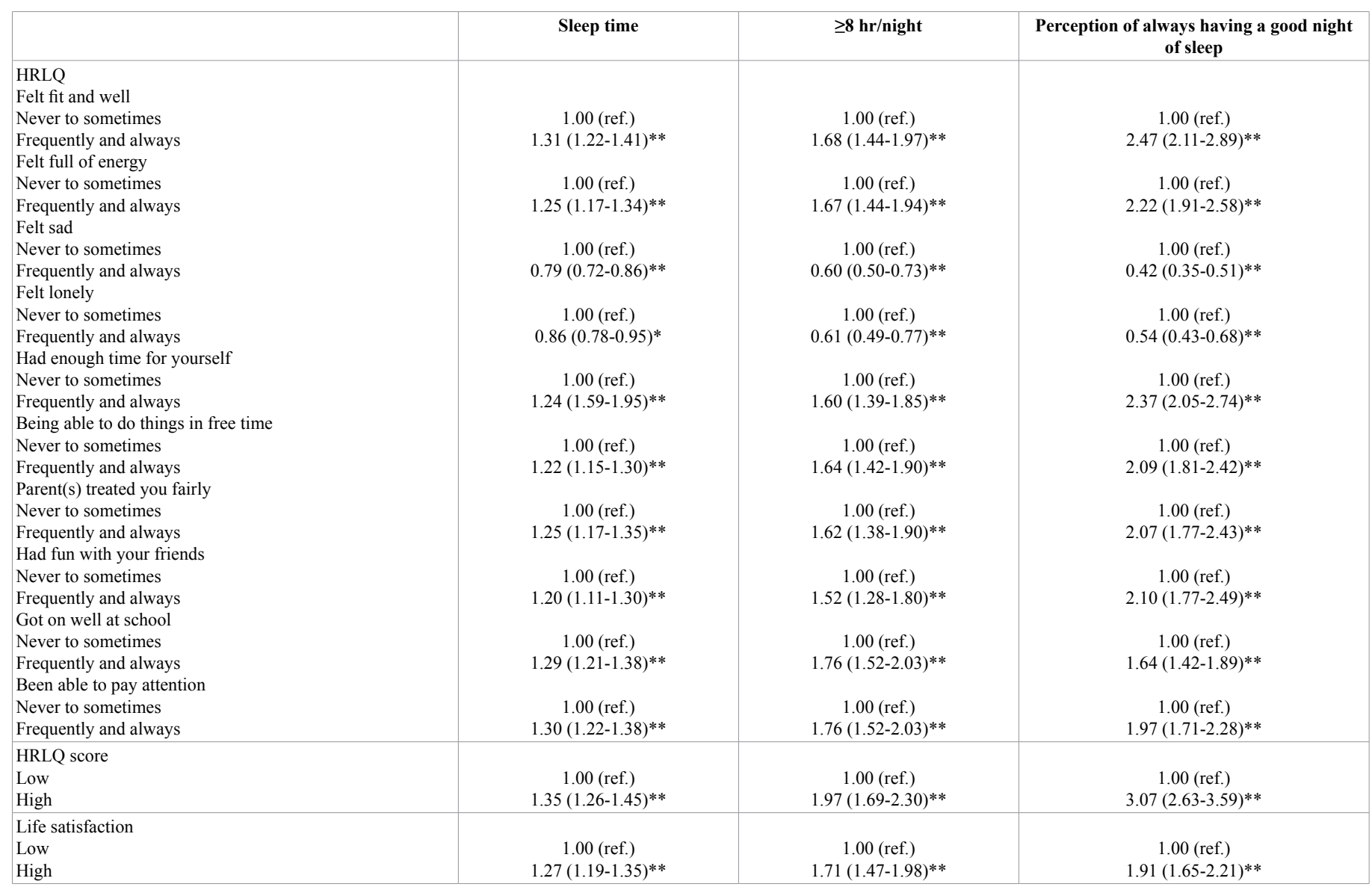

Analyses were adjusted for age, gender and health perception.

$* p<0.01, p<0.001$

poorer as well as their reported life satisfaction [36-38,52,57,58]. As for the analyse of sleep parameters, although in some previous studies the sleep dimension under analyse was sleep deprivation (as stated for the difference between sleep duration on week days and weekends) and the present study focuses sleep duration and perception of sleep quality $[16,18-20,26,27]$, the present results confirm the importance of sleeping eight hours or more in the perception of wellbeing and life satisfaction during adolescence, this study adds to previous studies that not only the duration and the perception of a good quality of sleep are equally important, but that the pattern of association of these two parameters with health outcomes is similar, either considering HRQL/ KIDScreen-10 as a global score, either consider each of the 10 items individually. Although gender and age differences are often reported in the literature, in the present analysis even after adjusting for age, gender and health perception, both the number of sleeping hours and the perceived quality of sleep remained significant and positively correlated with HRQL/KIDScreen-10 score and life satisfaction , moreover this relation occurred significantly for all the single items of HRQL, positively whenever the item was positively oriented and negatively in the case of feeling sad and lonely.

\section{Conclusion}

The present results add to previous ones that both the duration and the perceived quality of sleep have impact upon the perception of quality of life and the perception of life satisfaction. These results are substantially important for sleep hygiene and for recommendations for adolescents, parents, health and education professionals and public policies. It is now widely recommended that adolescents must sleep at least 8 hours per night, what this study allow to recommend is that the perception of quality of that sleep is equally important for the perception of wellness and life satisfaction [1-3,17,18 ], and this leads to another set of recommendations for an adequate sleep hygiene, that include not exercising or practising sports in the evenings [5,21], avoiding conflicts at home in the evenings and not going to bed worried [61,62], not having caffeine and other energetic drinks in the evening [20], not abusing screen time after dinner or in bed $[5,16,19]$. This recommendations are important to assure sleep duration and perceived quality and therefore the perception of wellness and life satisfaction, having an additional impact on school satisfaction and academic success [16]. Public health policies could therefore include sleep related information, education and behaviour change in this area, targeting school aged children and adolescents and their families. This measures would contribute for people (especially children and adolescents) wellbeing, health, and school achievement, especially regarding contemporary lifestyles that include broadly all the technologies of information and communication that increase the amount of time spent using screens, together with the increasing amount of energetic products intake, that enable people to keep awaked, but have undermined effects upon their health.

\section{References}

1. Huang YS, Wang CH, Guilleminault C (2010) An epidemiologic study of sleep 
Matos MG (2017) Perception of quantity and quality of sleep and their association with health related quality of life and life satisfaction during adolescence

problems among adolescents in North Taiwan. Sleep Med 11: 1035-1042. [Crossref]

2. Moore M, Kirchner HL, Drotar D, Johnson N, Rosen C, et al. (2011) Correlates of adolescent sleep time and variability in sleep time: the role of individual and health related characteristics. Sleep Med 12: 239-245. [Crossref]

3. Langberg JM, Dvorsky MR, Marshall S, Evans SW (2013) Clinical implications of daytime sleepiness for the academic performance of middle school-aged adolescents with attention de?cit hyperactivity disorder. J Sleep Res 22: 542-548.

4. Kuriyan R, Bhat S, Thomas T, Vaz M, Kurpad AV (2007) Television viewing and sleep are associated with overweight among urban and semi-urban South Indian children. Nutr J 6: 25. [Crossref]

5. Padez C, Mourao I, Moreira P, Rosado V (2009) Long sleep duration and childhood overweight/obesity and body fat. Am J Hum Biol 21: 371-376. [Crossref]

6. Araújo J, Severo M, Ramos E (2012) Sleep duration and adiposity during adolescence. Pediatrics 130: e1146-1154. [Crossref]

7. Mitchell JA, Pate RR, España-Romero V, O'Neill JR, Dowda M, et al. (2013) Moderateto-vigorous physical activity is associated with decreases in body mass index from ages 9 to 15 years. Obesity (Silver Spring) 21: E280-293. [Crossref]

8. Javaheri S, Storfer-Isser A, Rosen CL, Redline S (2011) Association of short and long sleep durations with insulin sensitivity in adolescents. J Pediatr 158: 617-623. [Crossref]

9. Paciência I, Barros H, Araújo J, Ramos E (2013) Association between sleep duration and blood pressure in adolescents. Hypertens Res 36: 747-752.

10. Lewandowski AS, Palermo TM, De la Motte S, Fu R (2010) Temporal daily associations between pain and sleep in adolescents with chronic pain versus healthy adolescents. Pain 151: 220-225. [Crossref]

11. Auvinen JP, Tammelin TH, Taimela SP, Zitting PJ, Järvelin MR, et al. (2010) Is insufficient quantity and quality of sleep a risk factor for neck, shoulder and low back pain? A longitudinal study among adolescents. Eur Spine J 19: 641-649. [Crossref]

12. Valrie CR, Bromberg MH, Palermo T, Schanberg LE (2013) A systematic review of sleep in pediatric pain populations. J Dev Behav Pediatr 34: 120-128. [Crossref]

13. Paiva T, Cunhal P, Cunhal M (2008) Sleep schedules and academic success in Technical University Students. $J$ Sleep Res.

14. Quevedo-Blasco VJ, Quevedo-Blasco R (2011) Infuencia del grado de somnolencia, cantidad y calidad de sueño sobre el rendimiento académico en adolescentes. Int J Clin Health Psychol 11: 49-65.

15. Gomes AA, Tavares J, de Azevedo MH (2011) Sleep and academic performance in undergraduates: a multi-measure, multi-predictor approach. Chronobiol Int 28 786-801.

16. Matos M, Gaspar T, Tomé G, Paiva T (2015) Sleep variability and fatigue in adolescents: Associations with school-related features. Int J Psych Pp: 1-9.

17. Kalak N, Lemola S, Brand S, Holsboer-Trachsler E, Grob A (2014) Sleep duration and subjective psychological well-b eing in adolescence: a longitudinal study in Switzerland and Norway. Neuropsychiatr Dis Treat 10: 1199-1207.

18. Paiva T, Gaspar T, Matos MG (2015) Sleep deprivation in adolescents: correlations with health complaints and health-related quality of life. Sleep Med 16: 521-527. [Crossref]

19. Paiva T, Gaspar T, Matos MG (2013) Sleep deprivation correlations with risk behaviors in adolescents: results from a Portuguese national survey. Sleep Medicine 1: e-32-e33.

20. Matos MG, Paiva T, Costa D, Gaspar T, Galvao D (2016) Caffeine, Sleep Duration and Adolescents' Perception of Health Related Quality of Life. British J Educ Soc \& Behav Sci 16: 1-9.

21. Al-Hazzaa HM, Musaiger AO, Abahussain NA, Al-Sobayel HI, Qahwaji DM (2013) Lifestyle correlates of self-reported sleep duration among Saudi adolescents: a multicenter school-based cross-sectional study. Child Care Health Dev.

22. Bel S, Michels N, De Vriendt T, Patterson E, Cuenca-García M, et al. (2013) Association between self-reported sleep duration and dietary quality in European adolescents. $\mathrm{Br} \mathrm{J}$ Nutr 14: 1-11.

23. O'Brien EM, Mindell JA (2005) Sleep and risk-taking behavior in adolescents. Behav Sleep Med 3: 113-133. [Crossref]

24. Yen CF, King BH, Tang TC (2010) The association between short and long nocturnal sleep durations and risky behaviours and the moderating factors in Taiwanese adolescents. Psychiatry Res 179: 69-74.

25. Ivarsson M, Anderson M, Åkerstedt T, Lindblad F (2013) The effect of violent and nonviolent video games on heart rate variability, sleep, and emotions in adolescents with different violent gaming habits. Psychosom Med 75: 390-396. [Crossref]

26. Paiva T, Gaspar T, Matos MG (2015) Sleep deprivation, sleep stealers and risk behaviors in Portuguese adolescents-a cross cultural comparison. MOJ Public Health.

27. Paiva T, Gaspar T, Matos MG (2016) Mutual relations between sleep deprivation, sleep stealers and risk behaviours in adolescents. Sleep Sci 9: 7-13. [Crossref]

28. Popovici I, French MT (2013) Binge drinking and sleep problems among young adults. Drug Alcohol Depend 132: 207-215. [Crossref]

29. Olds T, Blunden S, Petkov J, Forchino F (2010) The relationships between sex, age, geography and time in bed in adolescents: a meta-analysis of data from 23 countries. Sleep Med Rev 14: 371-378. [Crossref]

30. Merikanto I, Lahti T, Puusniekka R, Partonen T (2013) Late bedtimes weaken school performance and predispose adolescents to health hazards. Sleep Med 14: 1105-1111. [Crossref]

31. Palermo TM, Fonareva I, Janosy NR (2008) Sleep quality and efficiency in adolescents with chronic pain: relationship with activity limitations and health-related quality of life. Behav Sleep Med 6: 234-250. [Crossref]

32. Tham SW, Holley AL, Zhou C, Clarke GN, Palermo TM (2013) Longitudinal course andrisk factors for fatigue in adolescents: the mediating role of sleep disturbances. $J$ Pediatr Psychol 38: 1070-1080.

33. Holmberg LI, Hellberg D (2008) Behavioral and other characteristics of relevance for health in adolescents with self-perceived sleeping problems. Int J Adolesc Med Health 20: 353-365. [Crossref]

34. Bakker RJ, van de Putte EM, Kuis W, Sinnema G (2009) Risk factors for persistent fatigue with significant school absence in children and adolescents. Pediatrics 124 e89-95. [Crossref]

35. Brand S, Kalak N, Gerber M, Clough PJ, Lemola S, et al. (2016) During early and midadolescence, greater mental toughness is related to increased sleep quality and quality of life. J Health Psychol 21: 905-915. [Crossref]

36. Gaspar T, Matos M, Ribeiro JL, Leal I, Erhart M, et al. (2012) Health-related quality of life in children and adolescents: subjective well-being. Span J Psychol 15: 177-186.

37. Ravens-Sieberer U, Gosch A, Abel T, Auquier P, Bellach BM, et al. (2001) Quality of life in children and adolescents: a European public health perspective. Soz Praventivmed 46: 294-302. [Crossref]

38. Ravens-Sieberer U, Gosch A, Rajmil L, Erhart M, Bruil J, et al. (2005) KIDSCREEN-52 quality-of-life measure for children and adolescents. Expert Rev Pharmacoecon Outcomes Res 5: 353-364. [Crossref]

39. Dewald JF, Meijer AM, Oort FJ, Kerkhof GA, Bögels SM (2010) The influence of sleep quality, sleep duration and sleepiness on school performance in children and adolescents: A meta-analytic review. Sleep Med Rev 14: 179-189. [Crossref]

40. Carskadon MA (2004) Sleep deprivation: health consequences and societal impact. Med Clin North Am 88: 767-776. [Crossref]

41. Sexton-Radek K (2013) Adolescent Sleep Quality Measured During Leisure Activities. Health Psychol Res 1: e23. [Crossref]

42. Randler C (2011) Association between morningness-eveningness and mental and physical health in adolescents. Psychol Health Med 16: 29-38. [Crossref]

43. Delgado-Prieto P, Díaz-Morales JF, Escribano Barreno C, Collado Mateo MJ, Randler C (2012) Morningness-eveningness and health-related quality of life among adolescents. Span J Psychol 15: 15613-1523. [Crossref]

44. Tzischinsky O, Shochat T. Eveningness, sleep patterns, daytime functioning and quality of life in Israeli adolescents. Chronobiol Int 2011; 28:743-59.

45. Talbot LS, McGlinchey EL, Kaplan KA, Dahl RE, Harvey AG (2010) Sleep deprivation in adolescents and adults: changes in affect. Emotion 10: 831-841. [Crossref]

46. Lovato N, Gradisar M, Short M, Dohnt H, Micic G (2013) Delayed sleep phase disorder in an Australian school-based sample of adolescents. J Clin Sleep Med 9: 939944. [Crossref]

47. Fredriksen K, Rhodes J, Reddy R, Way N (2004) Sleepless in Chicago: tracking the effects of adolescent sleep loss during the middle school years. Child Dev 75: 84-95. [Crossref]

48. Roberts RE, Roberts CR, Duong HT (2009) Sleepless in adolescence: prospective data on sleep deprivation, health and functioning. J Adolesc 32: 1045-1057. [Crossref]

49. Roberts RE, Duong HT (2014) The prospective association between sleep deprivation 
and depression among adolescents. Sleep 37: 239-244. [Crossref]

50. Chorney DB, Detweiler MF, Morris TL, Kuhn BR (2008) The interplay of sleep disturbance, anxiety, and depression in children. $J$ Pediatr Psychol 33: 339-348. [Crossref]

51. Rhie SK, Chae KY (2013) Impact of sleep duration on emotional status in adolescents. $J$ Depress Anxiety 2: 138.

52. Matos MG, Simões C, Reis M, Camacho I (2014) Equipa Aventura Social. The health of Portuguese adolescents in times of recession. Report of the 2014 HBSC study. Lisbon: CMDT \& FMH; 2015.

53. Currie C, Zanotti C, Morgan A, Currie D, de Looze M, et al. (2010) Social determinants of health and well-being among young people. Health Behaviour in School-aged Children (HBSC) study: International Report from the 2009/2010 survey. Copenhagen: WHO Regional O?ce for Europe.

54. Roberts C, Freeman J, Samdal O, Schnohr CW, de Looze ME, et al. (2009) The Health Behaviour in School-aged Children (HBSC) study: methodological developments and current tensions. Int J Pub Heal 2: 140-150.

55. Hirshkowitz M, Whiton K, Albert SM, Alessi C, Bruni O, et al. (2015) National Sleep Foundation's sleep time duration recommendations: methodology and results summary. Sleep Health 1: 40-43.

56. Ravens-Sieberer U, Erhart M, Rajmil L, Herdman M, Auquier P (2010) Reliability, construct and criterion validity of the KIDSCREEN-10 score: a short measure for children and adolescents' well-being and health-related quality of life. Quality of Life Research 19: 1487-1500.

57. Gaspar T, Ribeiro J, Leal I, Matos MG (2008) Promoção de Qualidade de Vida em Crianças e Adolescentes (Promoting health related Quality of life in children and adolescents). Psicol Saúde Doenças 9: 55-71.

58. Matos MG, Gaspar T, Simoes C (2012) Health-related quality of life in Portuguese children and adolescents. Psicologia-Reflexao e Critica 25: 230-237.

59. Buunk AP, Bennenbroek FT, Stiegelis HE, van den Bergh AC, Sanderman R, et al (2012) Follow-up effects of social comparison information on the quality of life of cancer patients: the moderating role of social comparison orientation. Psychol Health 27: 641-654. [Crossref]

60. Idler EL, Benyamini Y (1997) Self-rated health and mortality: a review of twenty-seven community studies. J Heal Soc Behav 38: 21-37.

61. Matos MG, Gaspar T, Cruz J, Neves AM (2013) New Highlights About Worries, Coping, and Well-being During Childhood and Adolescence. Psychology Research 3: 252-260.

62. Matos MG, Paiva T, Pinto RT (2013) Equipa do Projecto Aventura Social. A saúde dos jovens em idade escolar e o sono: problemáticas, actores e contextos (Young people and sleep problems, actors and contexts) In Paiva, T., Andersen, M. L., \& Tufik, S. (Eds.) 2013, O Sono e a Medicina do Sono. (Sleep and Sleep medicine).

Copyright: (C2017 Matos MG. This is an open-access article distributed under the terms of the Creative Commons Attribution License, which permits unrestricted use, distribution, and reproduction in any medium, provided the original author and source are credited. 